\title{
Removal of fluoride from an aqueous solution by batch and column process using activated carbon derived from iron infused Pisum sativum peel: characterization, Isotherm, kinetics study
}

\author{
Naincy Sahu, Chandra Bhan, Jiwan Singh ${ }^{\dagger}$ \\ Department of Environmental Science, Babasaheb Bhimrao Ambedkar University, Lucknow-226025, India
}

\begin{abstract}
The present study investigated the adsorption efficiency of magnetic activated carbon was synthesized by waste biomass of Pisum sativum (peel) and pyrolysis at $500^{\circ} \mathrm{C}$ temperature (MPPAC-500). Derived activated carbon was applied for removal of fluoride from aqueous solution. The MPPAC-500 was characterized by Fourier Transform Infrared Spectroscopy (FTIR), Scanning Electron Microscopy (SEM), zeta potential, X-ray Diffraction (XRD) and Particle Size Analyser. The fluoride sequestration study was performed in both batch and column systems. The batch adsorption study was focused on parameter like, adsorbent dose, contact time, $\mathrm{pH}$ and initial fluoride concentrations. The maximum capacity of fluoride removal was $\mathrm{q}_{\mathrm{o}}=4.71(\mathrm{mg} / \mathrm{g})$. Freundlich isotherm model $\left(\mathrm{R}^{2}-0.995\right)$ obeyed better than Langmuir $\left(\mathrm{R}^{2}-0.979\right)$ model. The $R_{\mathrm{L}}$ values observed between 0-1 $\left(\mathrm{R}_{\mathrm{L}}-0.057\right)$ inferred the favourable adsorption. Pseudo-second-order model favoured well than pseudo-first-order in the whole experimental data. In case of column study was performed at two different bed height $5 \mathrm{~cm}$ and $10 \mathrm{~cm}$ having flow rate of $5 \mathrm{~mL} / \mathrm{min}$ as well as $10 \mathrm{~mL} / \mathrm{min}$. The breakthrough curve and column data were interpreted by Thomas, Adams-Bohart, Yoon-Nelson and Clark model. These finding showed that MPPAC-500 has potential adsorptive capacity for fluoride removal from aqueous solutions in batch and column systems.
\end{abstract}

Keywords: Activated carbon, Adsorption, Column study, Fluoride removal, Pea peel

\section{Introduction}

Excessive and dearth presence of Fluoride $(\mathrm{F})$ in groundwater exposed more than two hundred million people across the world [1]. Many countries like China, India, Nigeria, Kenya, Pakistan, South America, Africa and Sri Lanka are facing severe problem of $\mathrm{F}^{-}$contamination in groundwater [2, 3]. According to WHO [4] $1.5 \mathrm{mg} / \mathrm{L}$ is maximum concentration of fluoride in water for drinking purpose. Fluoride act as double edged sword like element in water as lower concentration of $\mathrm{F}^{-}$is essential for human health, but its concentration more than $1.0 \mathrm{mg} / \mathrm{L}$ leads fluorosis related dental and skeletal in which teeth enamel and bone tissues get harmed because of its strong attraction with calcium found in teeth and bones [5].

Fluoride is naturally present in earth crust and rocks and it reached to the groundwater by slow leaching of fluoride containing

(1) This is an Open Access article distributed under the terms of the Creative Commons Attribution Non-Commercial License (http://creativecommons.org/licenses/by-nc/3.0/) which permits unrestricted non-commercial use, distribution, and reproduction in any medium, provided the original work is properly cited.

Copyright (C) 2021 Korean Society of Environmental Engineers parent rocks (viz. granite, basalt, synginte etc.) and minerals such as biotite, fluorite topaz [6]. Therefore, the natural geological sources are eventually responsible for reaching of fluoride to groundwater. Besides natural sources pharmaceuticals, cosmetics, effluents from fertilizers, metal processing units, semiconductors, and glass manufacturing factories are also contributing in reaching of fluoride to the surface water and groundwater [7]. Globally about more than 20 developed and developing nations like USA, Africa and Asia, where fluorosis became endemic, wherever China, Sri Lanka, India and Rift Valley countries of Africa are badly affected. In India, it has been reported that about 17 states are prevalently affected by fluorosis specially Andhra Pradesh, Gujarat, Rajasthan, Haryana, Assam, Tamil Nadu and Uttar Pradesh [8]. At present about more than 1 million people of India are thought to be affected by endemic fluorosis [9]. Therefore, today defluoridation of water became a necessity for vital human health by feasible technologies. Defluorination of water has been conducted by applying different

Received May 15, 2020 Accepted August 27, 2020

${ }^{\dagger}$ Corresponding author

Email: jiwansingh95@gmail.com

Tel: +91-7376157206

ORCID: 0000-0003-3851-7331 
conventional technologies such as membrane filtration, reverse osmosis, ion exchange, electrodialysis, flotation and adsorption. However, among these only few technologies can be applied at large scale because these technologies require high initial operating investment and maintenance. Therefore, there is a need to focus on cost effective and efficient technologies for the treatment of fluoride containing water. Adsorption is one of centre of focus of many researchers now days because of its cost-effectiveness, ease in operation, less chemical consumption, and better efficiency [10].

From the literature study, it is found that number of materials have been used for fluoride adsorption like oxides of Fe-Al [11], Al-impregnated carbon [12], activated charcoal, Mn-Ce oxide [13], composites of biopolymer [14], agricultural waste [15] , algal biomass, leaf biomass, biochar [16]. Activated and modified carbon is well known adsorbent for removal of pollutants from the water and wastewater due to its large surface area, good porosity, stable chemical characters [17]. Impregnation of $\mathrm{Fe}(\mathrm{III})$ with activated carbon enhances the adsorption ability ion aqueous solutions. The $\mathrm{Fe}(\mathrm{III})$ containing material bound with carbonyl groups, amine, carboxylic and hydroxyl groups through complexation reaction [18]. The different adsorbents having their adsorption capacity were reported for fluoride adsorption such as Cerium impregnated activated carbon (4.6 mg/g) [1], activated carbon (6.5 mg/g) [19], Zirconium doped activated carbon (5 mg/g) at $4 \mathrm{pH}$ [20], $\mathrm{SnO}_{2}$ doped activated carbon (4.6 mg/g) [21] and $\mathrm{CaCl}_{2}$ modified activated carbon $(2.1 \mathrm{mg} / \mathrm{g})$ [22].

In this study, authors attempt to prepare iron based activated carbon from the kitchen waste pea (pea peel) for the removal of fluoride by batch as well as column process that is the novelty of this research work.

\section{Materials and Methods}

\subsection{Chemicals and Reagents}

In this study magnetic adsorbent was prepared from the peel of pea (Pisum sativum) collected from the local vegetable market and grains separated from peel. The analytical grade chemicals and reagents were used in present study (sodium fluoride, solution of Ionic strength adjuster (ISA) solution, hydrochloric acid ( $\mathrm{HCl}$ ), ferric chloride $\left(\mathrm{FeCl}_{3}\right)$, sodium hydroxide $(\mathrm{NaOH})$,) were acquired from sigma Aldrich and thermo fisher scientific.

\subsection{Synthesis of Activated Carbon}

Activated carbon prepared from the pea peel according to the method explained by Lung et al. [23]. The collected pea peel was washed several times to eliminate the dust particles followed by drying at $80^{\circ} \mathrm{C}$ for $24 \mathrm{~h}$, after that it was ground and sieved in fraction of $0.25 \mathrm{~mm}$ mesh. The material was prepared in 1:10 ratio, 1 part is pea peel and 10 part is ferric chloride $\left(\mathrm{FeCl}_{3}\right)$ solution, then the mixture was stirrer for 240 mins and kept overnight for the mixing of $\mathrm{FeCl}_{3}$ with pea peel powder. The excess iron solution was separated by vacuum filtration and the obtained solid material dried for $24 \mathrm{~h}$ at $80^{\circ} \mathrm{C}$. The material was then filled in the quartz crucible with $100 \mathrm{ml}$ capacity and capped with fitted lid then pyrolyzed by using muffle furnace at $500^{\circ} \mathrm{C}$ temperature for $2 \mathrm{~h}$.
The obtain Activated Carbon was washed number of times with distilled water and then oven dried for $12 \mathrm{~h}$. The dried activated carbon homogenized and used for the removal of Fluoride. In this study synthesized pea peel magnetic activated carbon was termed as PPMAC-500.

\subsection{Characterization of the Bioadsorbent}

SEM (Scanning electron microscope), (JSM-6490 LV, JEOL, JAPAN) equipped with EDS used to determine surface analysis of the synthesized adsorbent (PPMAC-500). Surface functional group of the adsorbent observed by using Fourier- transform-infrared-spectroscopy (FTIR), (NICOLET 6700, Thermo Fisher Scientific, USA). X-Ray diffractometer (PW 3040/60 Pan Analytical Nether Land) was used for the analysis of crystalline structure of the activated carbon. The activated carbon scanned in the range $10^{\circ}$ to $90^{\circ}$ with $2^{\circ} \mathrm{min}^{-1}$ speed rate. Zeta nano-sizer (model no-Nano-ZS90, Malvern Instrument) used for observation of stability and particles size distribution by after dissolving activated carbon in ethanol. Point zero charge on the surface of adsorbent was also analysed.

\subsection{Experimental Batch Adsorption Design}

All batch experiment performed by adding of decided MPPAC-500 doses (1 to $4 \mathrm{~g} / \mathrm{L}$ ) having $50 \mathrm{~mL}$ solution of fluoride with varying concentration ( 5 to $20 \mathrm{mg} / \mathrm{L}$ ) in a $250 \mathrm{~mL}$ of Erlenmeyer flask. The flasks were shaken at constant speed (100 rpm) in an orbital shaker at ambient temperature. After adsorption, samples were collected at regular interval differences and then filtered, residual concentration of fluoride analysed by using fluorimeter (EUTECH ION $6^{+}$THERMO SCIENTIFIC, U.S.A. Whole batch experiment was done at ambient temperature except (from temperature values $25^{\circ} \mathrm{C}$ to $55^{\circ} \mathrm{C}$ and $\mathrm{pH}$ study conducted with different $\mathrm{pH}$ (2 to $10 \mathrm{pH}$ ). A pH of the fluoride solution was maintained by $0.1 \mathrm{M}$ hydrochloric acid and $0.1 \mathrm{M}$ sodium hydroxide solution. All batch adsorption studies were conducted in triplicates to minimize the error of the data. The removal percentage $(\mathrm{Re})$ and adsorption capacity $\left(\mathrm{q}_{\mathrm{t}}\right)$ of fluoride were determined by Eq. (1) and (2), respectively.

$$
\begin{gathered}
R e=\left(\frac{C_{o}-C_{e}}{C_{o}}\right) \times 100 \\
Q t=\left(\frac{C_{o}-C_{e}}{w}\right) \times V
\end{gathered}
$$

Where, $C_{o}$; Initial concentration, $C_{e}$; final concentration, $w$; adsorbent mass, $V$; solution volume.

\subsection{Experimental Column Design and Procedure}

The continuous column adsorption performed for the removal of on MPPAC-500 borosilicate glass column at room temperature and neutral $\mathrm{pH}$. Vertical glass column was used for fixed bed column study with $1.5 \mathrm{~cm}$ diameter and $38.3 \mathrm{~cm}$ length is shown in Fig. 1. Column were performed in downflow mode. Two different quantities of MPPAC-500 were packed at $5 \mathrm{~cm}$ and $10 \mathrm{~cm}$ bed height with used doses $4.8 \mathrm{~g}$ for $5 \mathrm{~cm}$ and $9.6 \mathrm{~g}$ for $10 \mathrm{~cm}$ bed depth. 


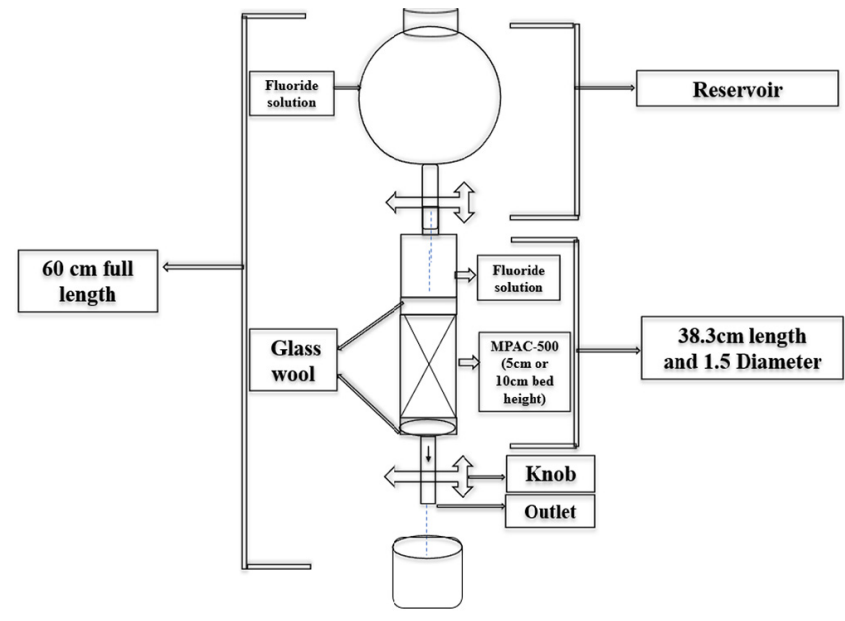

Fig. 1. Experimental fixed bed column setup.

The MPPAC-500 was packed by the $1 \mathrm{~cm}$ layer of glass wool and sieved with pore size $0.5 \mathrm{~mm}$ were placed at both side (up and down) of the column, which are used for the uniform flow. solution having $10 \mathrm{mg} / \mathrm{L}$ concentration was passed out from reservoir knob with $5 \mathrm{~mL} / \mathrm{min}$ and $10 \mathrm{~mL} / \mathrm{min}$ flow rate. The treated samples (5 mL) were collected at regular time interval. The main focus of column adsorption study to determined, how much volume of the effluent can treat at a time.

\subsubsection{Column data analysis}

\subsubsection{Breakthrough curve}

Breakthrough curve is used to check adsorption performance of the fixed-bed-column. The breakthrough point was taken until the outlet fluoride concentration was reaches $99.5 \%$ of inlet fluoride concentration. The breakthrough curve was expressed by plotting $\mathrm{C}_{\text {in }} / \mathrm{C}_{\text {out }}$ against contact time [24]. Where $C_{\text {in }}$ is the starting fluoride concentration and $C_{\text {out }}$ is the final fluoride concentration, respectively.

Total outlet volume, $\mathrm{V}_{\text {eff }}$ can be determined by the following Eq. (3).

$$
V_{\text {eff }}=Q \times t_{\text {total }}
$$

Where Q ( $\mathrm{mL} / \mathrm{min})$; flow rate in volume, $\mathrm{t}_{\text {total }}$; total flow time (min).

Total adsorbed amount of fluoride concentration, qtotal (mg) can be observed from the Eq. (4).

$$
q_{\text {total }}=\frac{Q}{1000} \int_{t=0}^{t=\text { total }} C_{a d} d t
$$

Adsorption capacity denotes by $\mathrm{q}_{\mathrm{e}}(\mathrm{mg} / \mathrm{g})$ can be found by the formula as given below.

$$
q_{e}=\frac{q_{\text {total }}}{m}
$$

where $m$ denotes dry amount of the adsorbent (g) filled in a column.

Total fluoride ions $\left(\mathrm{M}_{\text {total }}\right)$ delivered to the column is calculated from Eq. (6).

$$
M_{\text {total }}=C_{o} \times Q \times t_{\text {total }}
$$

Total removal percentage of fluoride ions can be calculated from Eq. (7).

$$
\text { Total fluoride removal } \%=\frac{m_{a d}}{m_{\text {total }}} \times 100
$$

Where $\mathrm{m}_{\mathrm{ad}}$ is the dry amount of adsorbent sent to the column.

\section{Results and Discussion}

\subsection{Characterization of MPPAC- 500}

\subsubsection{SEM and EDX}

The SEM and EDS analysis were conducted for morphological investigation of prepared adsorbent. Image shows that surface of iron modified biochar is rough and partially porous in nature as presented in Fig. 2(a). Surface roughness and porosity of adsorbent may determine the maximum adsorption sites that facilitate high adsorption of fluoride. After adsorption of fluoride the structure of adsorbent particle altered that is shown Fig. 2(b). The EDS analysis revealed that $\mathrm{C}, \mathrm{O}, \mathrm{Cl}$, and $\mathrm{Fe}$ are present in adsorbent in different proportion as shown in Fig. 5(c) and (d).

\subsubsection{FTIR}

The FTIR spectra of MPPAC-500 before and after uptake of fluoride, are shown in Fig. 2(c). The spectra of materials were observed from scanning of wavenumber ranged from $400-4,000 \mathrm{~cm}^{-1}$. The strong band observed 3,013. $7 \mathrm{~cm}^{-1}$ in MPPAC-500 before fluoride adsorption and 3,046.8 $\mathrm{cm}^{-1}$ in MPPAC-5000 after adsorption represent the $-\mathrm{CH}$ stretching vibration due to presence of methyl group. The peak ranged between $1,513.1$ to $1,578.7 \mathrm{~cm}^{-1}$ are due to $\mathrm{C}$ $=\mathrm{C}$ aromatic group [25]. The adsorption bands observed at 1,408.1 to $1,238.9 \mathrm{~cm}^{-1}$ could be assigned to $-\mathrm{OH}$ (hydroxyl) group vibration mode. The shifting of wavenumber from 1,108.7-1,059.9 $\mathrm{cm}^{-1}$ represent the $>\mathrm{C}=\mathrm{O}$ (ketone) group functioning during adsorption of fluoride. The adsorption band between $400 \mathrm{~cm}^{-1}$ to $500 \mathrm{~cm}^{-1}$ attributed to the Fe-O vibrations. The presence of Fe-O shows that the iron was present on the synthetic adsorbent [26].

\subsubsection{XRD}

The XRD pattern of MPPAC-500 before adsorption is shown in Fig. $2(\mathrm{~d})$. The XRD pattern observed in the $2 \theta$ range of $5-80^{\circ}$. The fine and sharp peaks of MPPAC-500 were found at $2 \theta$ range of 20-40 . Fig. 2(d) illustrates the XRD diffractogram pattern of iron coated adsorbent (MPPAC-500). The major and sharp peaks $23.58^{\circ}$, $31.04^{\circ}$ and $35.7^{\circ}, 40.48^{\circ}, 49.06^{\circ}$ and $53.72^{\circ}$ are resembling the presence of $\mathrm{Fe}_{3} \mathrm{O}_{4}[27,23]$. Similar peaks i.e. $30.2^{\circ}, 35.5^{\circ}$ and $53.6^{\circ}$ were reported for $\mathrm{Fe}_{3} \mathrm{O}_{4}$ [28]. A significant hump in the range of $20^{\circ}-40^{\circ}$ is depicted a crystalline graphitic structure [29].

\subsubsection{Zeta Potential}

Zeta potential of MPPAC-500 was studied at different $\mathrm{pH}$ (2-10) by using the (Zeta Nano Zs90, Malvern Instrument). The value 

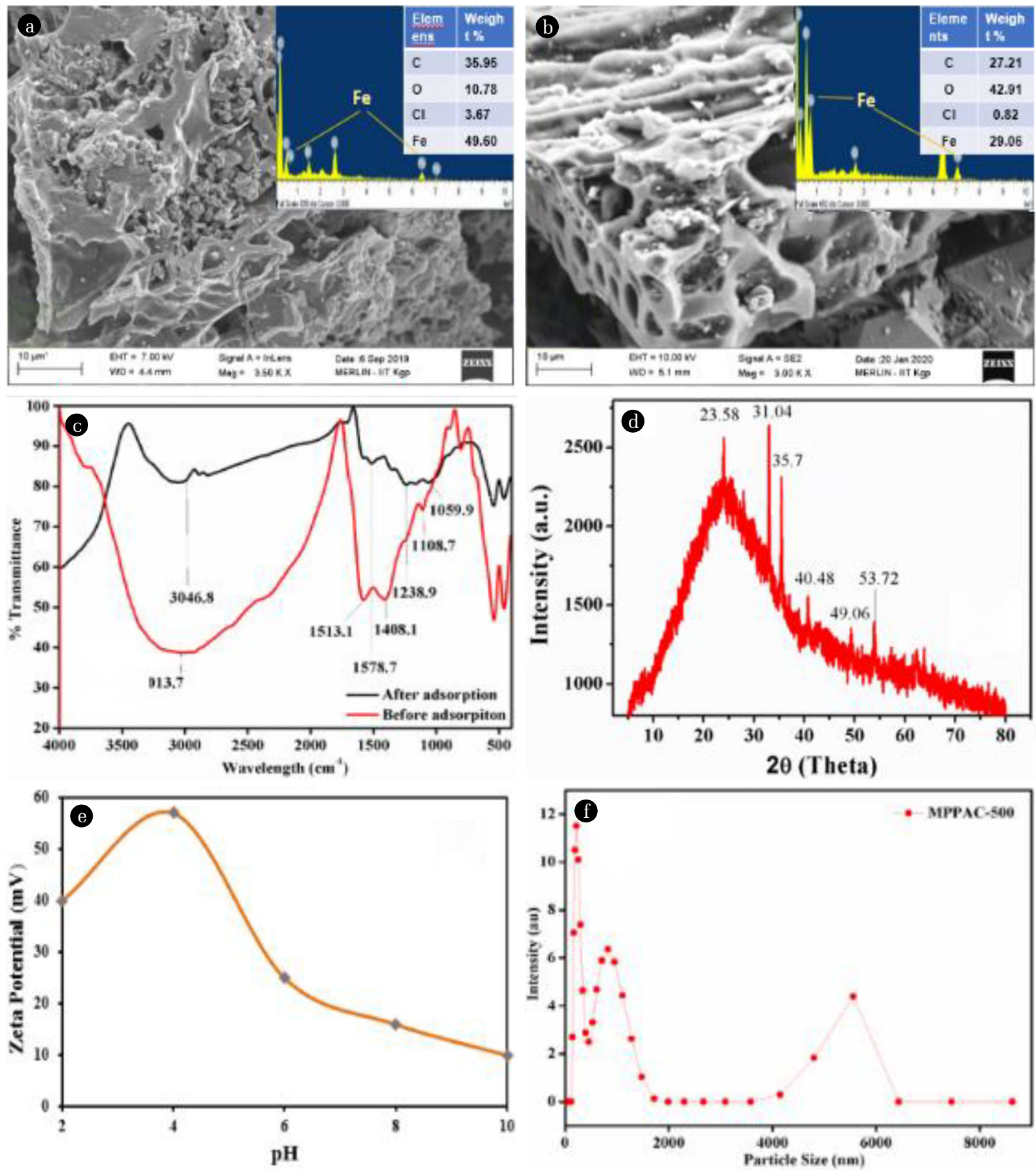

Fig. 2. SEM and EDS of MPPAC500 (a) before and (b) after adsorption, (c) FTIR spectra of MPPAC500, (d) XRD analysis, (e) Zeta Potential and (f) Particle Size Analysis of MPPAC500.

of Zeta potential indicates the stability or instability of the material in dispersed medium [30]. Zeta potential was found to be +56 $\mathrm{mV}$ at $\mathrm{pH}-4$ that is shown in Fig. 2(e). This value indicates that adsorbent is highly stable in acidic $\mathrm{pH}$ while at higher $\mathrm{pH}$, Zeta potential value was observed $+10 \mathrm{mV}$. Therefore, it is clear that the adsorbent MPPAC-500 is stable for the application of fluoride.

\subsubsection{PSA}

Particle size distribution of adsorbent is measured by several techniques such as based on light, ultrasound, electric field and centrifugation. In this study we have used the light-based measurement particle size distribution (Zeta Nano ZS90, Malvern). Fig. (f) shows the average particle size range $\sim 0.11$ to $0.30 \mu \mathrm{m}$, for 
first peak $20 \%$ particle in range $\sim 0.11 \mu \mathrm{m}$ and second peak 80 $\%$ of particles in $\sim 0.30 \mu \mathrm{m}$. Adsorbent MPPAC-500 has small average particle size distribution its mean synthesized adsorbent has high surface area that facilitate highest adsorption of adsorbate.

\subsection{6. $\mathrm{pH}_{\mathrm{ZPC}}$}

The $\mathrm{pH}_{\mathrm{ZPC}}$ value of synthesized MPPAC-500 was measured according to a described method by Singh et al. [31]. $\mathrm{pH}_{\mathrm{ZPC}}$ value was used to determine the surface charge of the adsorbent. Fig. S1 shows that $\mathrm{pH}_{\mathrm{ZPC}}$ of MPPAC-500 was found to be 2.8 and this pHzpc value indicates that surface of adsorbent is dominated with cationic groups. It means the adsorbent is acidic in nature. When $\mathrm{pH}$ of the solution does below the $\mathrm{pH}_{\mathrm{ZPC}}$, surface of the adsorbent contains positive charge while above the $\mathrm{pH}_{\mathrm{ZPC}}$ it contains negative charge.

\subsection{Batch Study}

\subsubsection{Effect of adsorbent dose}

Quantity of adsorbent plays crucial role in adsorption process. As given in Fig. 3(a) four varying doses 1, 2, 3, 4 g/L of MPPAC-500 were selected for the dose study for the removal of fluoride ions, while other parameters like starting concentration- $10 \mathrm{mg} / \mathrm{L}$, contact time- $470 \mathrm{~min}$, at neutral $\mathrm{pH}$ in an ambient temperature were maintained. It was observed that with increasing the dosage of the adsorbent from $1 \mathrm{~g} / \mathrm{L}$ to $4 \mathrm{~g} / \mathrm{L}$, the removal of fluoride increased from $78 \%$ to $99.5 \%$. The highest adsorption capacity was achieved to be $2.48 \mathrm{mg} / \mathrm{g}$, so that adsorbent dose $4 \mathrm{~g} / \mathrm{L}$ was selected for the further study. The results revealed that percentage removal of fluoride was increased with increasing the amount of adsorbent because of more active sites are available on MPPAC-500 for the removal of fluoride ions.

\subsubsection{Effect of $\mathrm{pH}$}

The $\mathrm{pH}$ of solution is the very crucial factor for adsorption process. In adsorption process, ionization potential, adsorbate speciation and surface charge of adsorbent are strongly affected by $\mathrm{pH}$ of aqueous solution [32]. In present study the adsorption of Fluoride on MPPAC-500 was investigated with varying $\mathrm{pH}$ (2.0 to 10), while all other experimental parameters were remained same including dose- $4 \mathrm{~g} / \mathrm{L}$, concentration-10 mg/L, temperature- $25^{\circ} \mathrm{C}$. Fig. 3(b) indicates that the maximum adsorption of Fluoride was achieved $100 \%$ at $\mathrm{pH} 2.0$ and it slightly decreased with increasing $\mathrm{pH}$ of the solution. It was perceived that adsorption of fluoride ions is good in the $\mathrm{pH}$ values 2.0 to 7.0 . At $\mathrm{pH} 7$ the maximum adsorption efficiency was found to be $96 \%$. The enhancement in adsorption efficiency may be happened due to fluoride ions are negatively charged and get attracted by the positively charged adsorbent. While at $\mathrm{pH} 10$ adsorption efficiency was $90.4 \%$. A slight decline in fluoride adsorption efficiency can be attributed due to $\mathrm{OH}^{-}$ions enhancement, that form aqua-complexes in alkaline solution [33].

\subsubsection{Effect of initial fluoride concentration with contact time on adsorption}

The effect of fluoride concentration was assessed with varying the starting concentration, taken from $5 \mathrm{mg} / \mathrm{L}$ to $20 \mathrm{mg} / \mathrm{L}$ at the neutral $\mathrm{pH}$ and at ambient temperature. As shown in Fig. 3(c). It was obtained that adsorption rate was declined from $99 \%$ to $87 \%$ with enhancing the concentration of fluoride from 5 to 20 $\mathrm{mg} / \mathrm{L}$. The highest adsorption capacity was observed to be $4.35 \mathrm{mg} / \mathrm{g}$. Further increasing the initial concentration of fluoride ions, removal percentage was decreased this may occur due to active sites on adsorbent surface were decreases after a saturation point [34].

To evaluate the effect of interaction time between fluoride ions and MPPAC-500, batch experiment was performed at several time intervals. Fig. 5(c) illustrates, the removal of fluoride increase with increasing contact time, after contact time of $300 \mathrm{~min}$, there is no further increment in fluoride adsorption so adsorption equilibrium was achieved at $300 \mathrm{~min}$ at which removal rate of fluoride was constant because adsorption of fluoride ions in aqueous solution on the surface of MPPAC-500 is equal to the desorption rate.
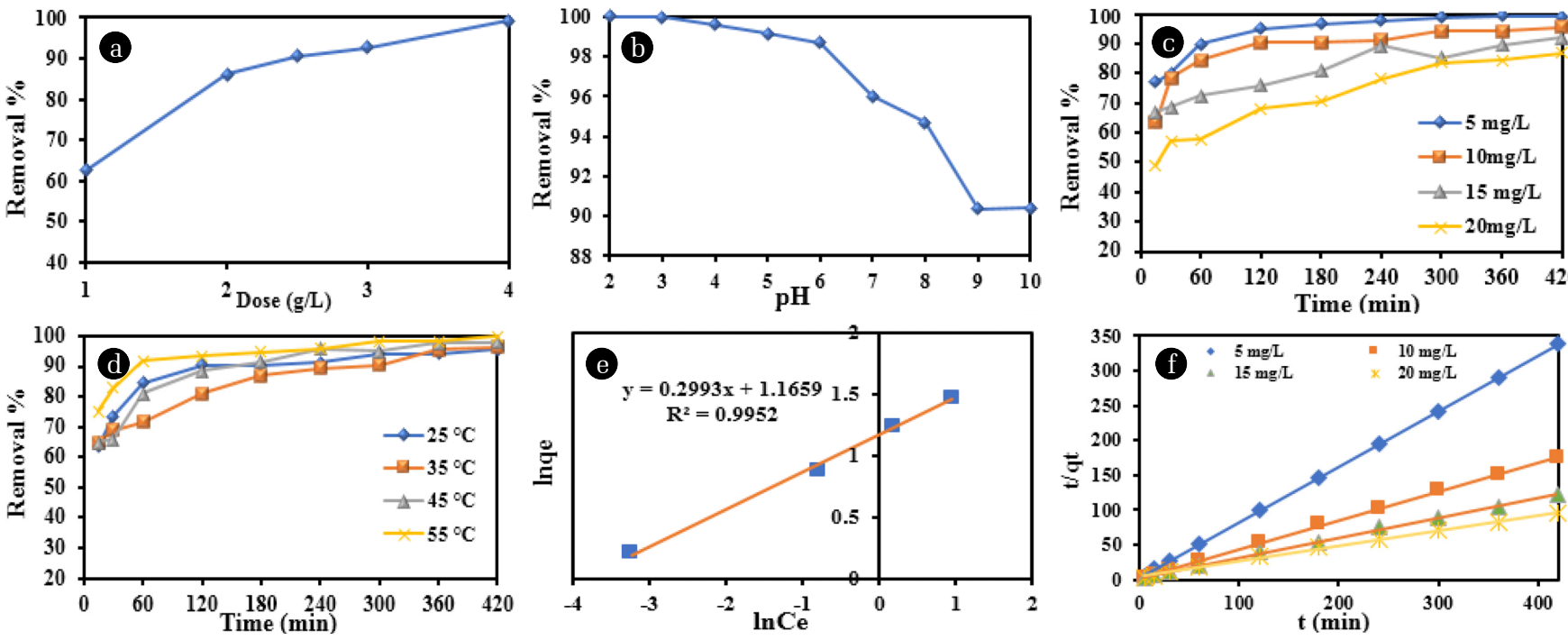

Fig. 3. (a) Effect of adsorbent dose, (b) effect of $\mathrm{pH}$ on adsorption, (c) effect of initial concentration of fluoride, (d) effect of temperature on adsorption, (e) Plot of Freundlich adsorption isotherm for MPPAC500 and (f) Plots of pseudo second order kinetic. 


\subsubsection{Effect of Temperature}

In an adsorption phenomenon temperature is a very important factor, which influence the reaction rate of it. The effect of the temperature was studied at different temperature range $\left(25^{\circ} \mathrm{C}, 35^{\circ} \mathrm{C}\right.$ $45^{\circ} \mathrm{C}$, and $55^{\circ} \mathrm{C}$ ) for the adsorption of fluoride on MPPAC-500, while all other parameters were kept at optimum conditions such as dose-4 g/L, concentration- $10 \mathrm{mg} / \mathrm{L}$. $\mathrm{pH}-7$, temperature- $25^{\circ} \mathrm{C}$. As shown in Fig. 3(d) the removal percentage of the adsorbate was increased with increasing temperature, which proves that adsorption process is endothermic. The adsorption of fluoride was slightly increased from $95 \%$ to $99 \%$ with enhancing temperature from $25^{\circ} \mathrm{C}$ to $55^{\circ} \mathrm{C}$, this happen might be due to various adsorbent required high temperature for activation of vacant sites on adsorbent at high temperature, many vacant sites are present on the surface of adsorbent, that need sometimes high or sometimes low temperature for activation [35].

\subsection{Isotherm}

An adsorption isotherm was applied to analysed the equilibrium relationship between adsorbate and adsorbent surface. Langmuir, Freundlich, Temkin were widely adapted for validity of adsorption phenomenon. The summarization of isotherm parameters is listed in Table 1.

Table 1. Parameters of Langmuir, Freundlich and Temkin Isotherm for the Fluoride lons Removal on to AC-500

\begin{tabular}{lcc}
\hline & $\mathrm{Q}_{0}(\mathrm{mg} / \mathrm{g})$ & 4.717 \\
Langmuir & $\mathrm{B}(\mathrm{L} / \mathrm{mg})$ & 3.355 \\
Isotherm & $\mathrm{R}_{\mathrm{L}}$ & 0.057 \\
& $\mathrm{R}_{2}$ & 0.979 \\
\hline \multirow{2}{*}{ Freundlich } & $\mathrm{K}_{\mathrm{F}}(\mathrm{mg} / \mathrm{g}(\mathrm{L} / \mathrm{mg}) 1 / \mathrm{n})$ & 3.206 \\
Isotherm & $\mathrm{N}$ & 3.345 \\
& $\mathrm{R}^{2}$ & 0.995 \\
Temkin & $\mathrm{K}_{\mathrm{T}}$ & 29.254 \\
Isotherm & $\mathrm{B}$ & 0.715 \\
& $\mathrm{R}^{2}$ & 0.945 \\
\hline
\end{tabular}

\subsubsection{Langmuir isotherm}

Langmuir model illustrate the monolayer adsorption between the adsorbent and adsorbate due to presence of active sites on the surface of adsorbent. Langmuir isotherm presumes that adsorption force and chemical interaction are similar. Langmuir isotherm express by the given Eq. (8).

$$
C_{e} / q_{e}=\frac{1}{Q_{o} b}+\left(\frac{1}{Q_{o}}\right)
$$

Where, $q_{e}$ denotes the quantity of fluoride adsorbed per unit gram of the adsorbent $\left(\mathrm{mg} / \mathrm{g}\right.$ ) and $C_{e}$ is the fluoride ion concentration at equilibrium $(\mathrm{mg} / \mathrm{L})$. Langmuir constant $\left(Q_{0}\right)$ and highest adsorption capacity of MPPAC-500 and adsorption rate are represented by $b$. The value $Q_{o}$ and $b$ can be obtained from plot of $C_{e} / q_{e}$ and $C_{e}$ [36] shown in the supplementary Fig. S2. Table 1 show the values of Langmuir isotherm parameter. $\mathrm{R}_{\mathrm{L}}$ equilibrium parameter known as dimensionless constant that is significant characteristic of the Langmuir isotherm, expressed as following Eq. (9).

$$
R_{L}=\frac{1}{1+b C_{o}}
$$

Where, $C_{o}$ and $b$ are stand for the starting fluoride concentration and Langmuir equilibrium constant, respectively. The $\mathrm{R}_{\mathrm{L}}$ value express the Langmuir isotherm type could be favourable $\left(0<\mathrm{R}_{\mathrm{L}}<10\right.$, $\left(\mathrm{R}_{\mathrm{L}}\right.$ =1) linear, $\left(R_{\mathrm{L}}>1\right)$ unfavourable, $\left(\mathrm{R}_{\mathrm{L}}=0\right)$ irreversible. The value of $R_{L}$ was found to be 0.057 that is calculated by given Eq. (9).

\subsubsection{Freundlich isotherm}

This isotherm represents the heterogeneous layer formation on the surface of adsorbent due to adsorption. Freundlich model equation is expressed by the given Eq. (10)

$$
l n q_{e}=\ln K_{F}+\left(\frac{1}{n}\right) C_{e} \ln C_{e}
$$

Where, at equilibrium quantity of fluoride (mg/g) and adsorbate concentration $(\mathrm{mg} / \mathrm{L})$ are denoted by $\mathrm{q}_{\mathrm{e}}$ and $\mathrm{C}_{\mathrm{e}}$. The $\mathrm{n}$ value illustrates the Freundlich isotherm favouring or not favouring, whereas $K_{F}$ represents the capacity $\left(\mathrm{mg} / \mathrm{g}(\mathrm{L} / \mathrm{mg})^{1 / 1}\right.$ ) of MPPAC-500 to adsorption fluoride. The heterogenous nature of adsorbent surface and adsorption intensity were calculated through the slope value between 0-1 was observed from the graph plotted $\ln q_{e}$ against $\ln C_{e}$. When the slope value is near about 0 , indicate that the surface of adsorbent is highly heterogenous. Plotted graph is illustrated in the Fig. 3(e) and obtained values are listed in Table 1.

The Freundlich constant $K_{F}$ value was 3.206 (mg/g(L/mg $\left.{ }^{1 / n}\right)$, which shows the biosorption capacity of adsorbent. The value of ' $n$ ' was also lying between 1 to 10 (n-4.92) which also favours the favourable adsorption process [37]

\subsubsection{Temkin isotherm}

This isotherm model gives information about interaction of adsorbent-adsorbate. This model assumes that adsorption heat of whole molecule will not remain same. Interaction between sorbate and sorbent decreases the heat during adsorption process due to uniform dispersal of binding energy [38]. Temkin isotherm represented in the Eq. (11).

$$
q_{e}=B \ln \left(A_{T}\right)+B \ln C_{e}
$$

Where, $q_{e}$ represents the quantity of fluoride adsorbed on MPPAC-500 $(\mathrm{g} / \mathrm{L})$ and $\mathrm{C}_{\mathrm{e}}$ is the concentration of fluoride. $B_{T}$ is constant for Temkin isotherm related to the adsorption heat $(\mathrm{L} / \mathrm{g})$. $A_{T}$ is Temkin isotherm equilibrium binding constant, which is dimensionless. Values of $A_{T}$ and $B$ presented in Table 1 and supplementary Fig. S3.

After comparing of these isotherm models, it is revealed that Freundlich model fitted well $\left(\mathrm{R}^{2}=0.995\right)$ than Langmuir model $\left(\mathrm{R}^{2}=0.979\right)$. Table 1 shows that $Q_{o}$ value of MPPAC-500 was $4.717 \mathrm{mg} / \mathrm{g}$ which is quite higher than data available in literature, vitex negundo plant carbon $1.150 \mathrm{mg} / \mathrm{g}$ [30], treated banana peel $0.395 \mathrm{mg} / \mathrm{g}$ and treated coffee husk $0.416 \mathrm{mg} / \mathrm{g}$ [39]. The $R_{L}$ values 
Table 2. Values of Intraparticle Diffusion Model and Thermodynamic

\begin{tabular}{|c|c|c|c|c|c|c|}
\hline \multicolumn{4}{|c|}{ Intraparticle diffusion model } & \multicolumn{3}{|c|}{ Thermodynamic } \\
\hline Co (mg/L) & Ki (mg/g.min $\left.{ }^{1 / 2}\right)$ & $\mathrm{C}\left(\mathrm{mg}^{-1}\right)$ & $\mathbf{R}^{2}$ & parameters & Temperature (K) & \\
\hline 5 & 0.013 & 1.004 & 0.76 & $\Delta \mathrm{G}^{\circ}(\mathrm{KJ} / \mathrm{mol})$ & & \\
\hline 10 & 0.032 & 1.818 & 0.71 & & 298 & 933338.5 \\
\hline 15 & 0.054 & 2.415 & 0.955 & & 308 & -96473.7 \\
\hline \multirow[t]{4}{*}{20} & 0.104 & 2.399 & 0.965 & & 318 & -99608.9 \\
\hline & & & & & 328 & -102744 \\
\hline & & & & $\Delta \mathrm{H}(\mathrm{J} / \mathrm{mol})$ & & 90.7889 \\
\hline & & & & $\Delta \mathrm{S}(\mathrm{J} / \mathrm{mol} \mathrm{K})$ & & 313.5209 \\
\hline
\end{tabular}

was ranged between 0-1 $\left(\mathrm{R}_{\mathrm{L}}-0.22\right)$ indicating the favourable fluoride adsorption onto MPPAC-500 [37].

\subsection{Adsorption Kinetics}

Adsorption kinetic quantifies the rate of reaction and adsorption mechanism involved in the uptake of fluoride onto MPPAC-500 [40]. Both kinetic models (pseudo-first-order and pseudo-second-order) and their parameters were applied for present experimental data. The rate constant of Fluoride adsorption is analysed from the reaction of Pseudo-first-order (PFO) given by Lagergren (1898) that is expressed by Eq. (12).

$$
\log \left(q_{e}-q_{t}\right)=\log q_{e}-\left(\frac{K_{1}}{2.3030}\right) \cdot t
$$

Where, $q_{e}$ denotes amount of fluoride adsorbed on MPPAC-500 at a point of equilibrium, $q_{t}$ is the amount of fluoride adsorbed at a time (min). $K_{1}$ is the fluoride adsorption constant rate. The $K_{1}$ value was obtained from the plot of $\log \left(\mathrm{q}_{\mathrm{e}}-\mathrm{q}_{\mathrm{t}}\right)$ and time (min) was given in supplementary Fig. S4.

The kinetics data of fluoride were also analysed through pseudo-second-order [31] and the equation for pseudo-second-order is given below.

$$
t / q_{e}=1 /\left(k_{2} q_{e} 2\right)+\left(1 / q_{e}\right) t
$$

Where, $k_{2}$ is stand for the pseudo-second-order constant $(\mathrm{g} / \mathrm{(mg}$ $\min$ ) and $q_{e}$ is the fluoride adsorption capacity. There values were found from the plot of $t / q_{t}$ against $t$ as represented in Fig. 3(f).

After comparing data of both kinetic models, it is confirmed that pseudo-second-order favoured better with adsorption data than pseudo-first-order. Values of both kinetics parameters are given in the supplementary Table S1.

\subsection{Intraparticle Diffusion Model}

Adsorption is considered as multi-step phenomenon because it includes transportation of solute from aqueous medium to the adsorbent surface and also solute diffusion through pores. Through the Intraparticle model, large amount of adsorbate present in solution are transferred to the adsorbent surface. The equation for Intraparticle diffusion model is expressed in the below.

$$
q_{t}=k_{i} t^{1 / 2}+C
$$

Where, $K i\left(\mathrm{mg} / \mathrm{g} \mathrm{min}^{1 / 2}\right)$ represents to the rate constant and $C$ is the constant, which related to thickness of boundary layer. Maximum value of constant indicates the maximum effect of boundary layer. The value of $K_{i}$ and $C$ can be determined from the $\mathrm{m}$ and $C$ of the plot of $q_{t}$ verses $t^{1 / 2}$. It was investigated from the Fig. 4(a) and Table 2, at each concentration linear plot of fluoride does not go through the origin, hence the diffusion rate was not only responsible for adsorption of fluoride. That means other mechanism may also affect the fluoride removal on MPPAC-500.

\subsection{Thermodynamics}

Thermodynamic study describes the role of temperature in adsorption process. Parameters related thermodynamic such as change in entropy $(\Delta S)$, change in enthalpy $(\Delta S)$ and change in Gibb's free energy $(\Delta G)$ for the adsorption of fluoride ions on adsorbent were determine by using following equation.

$$
\begin{gathered}
K_{c}=\frac{q_{e}}{C_{e}} \\
\ln K_{c}=\frac{\Delta S}{R}-\frac{\triangle H}{R T} \\
\triangle G=\triangle H-T \triangle S
\end{gathered}
$$

Where, $K$ is the thermodynamic distribution coefficient constant, While $T$ and $R$ denote temperature $(\mathrm{K})$ and universal gas constant, respectively in the reaction. $C_{e}$ and $q_{e}$ are fluoride ions in aqueous phase $(\mathrm{mg} / \mathrm{L})$ and adsorbed quantity of fluoride $(\mathrm{mg} / \mathrm{g})$ on MPPAC-500 at equilibrium. The changed entropy and changed enthalpy were obtained through the value of intercept and slope of the plot between $\ln K_{c}$ and 1/T (Fig. 4(b)). From the Table 2, it is evidenced that the reaction was spontaneous in nature due to negative value of Gibb's free energy. The positive value of enthalpy $(\Delta \mathrm{H})$ was $90.78 \mathrm{KJ} / \mathrm{mol}$, it also stated that the fluoride uptake onto MPPAC-500 was endothermic in nature.

\subsection{Column Experiment}

\subsubsection{Effect of packed column bed length}

The breakthrough curve was obtained at two different bed depth $5 \mathrm{~cm}$ and $10 \mathrm{~cm}$ at a fixed flow rate $5 \mathrm{~mL} / \mathrm{min}$ and starting concentration $10 \mathrm{mg} / \mathrm{L}$. The breakthrough curve and other parameter are depicted in Fig. 4(c) and interpreted values of breakthrough parame- 

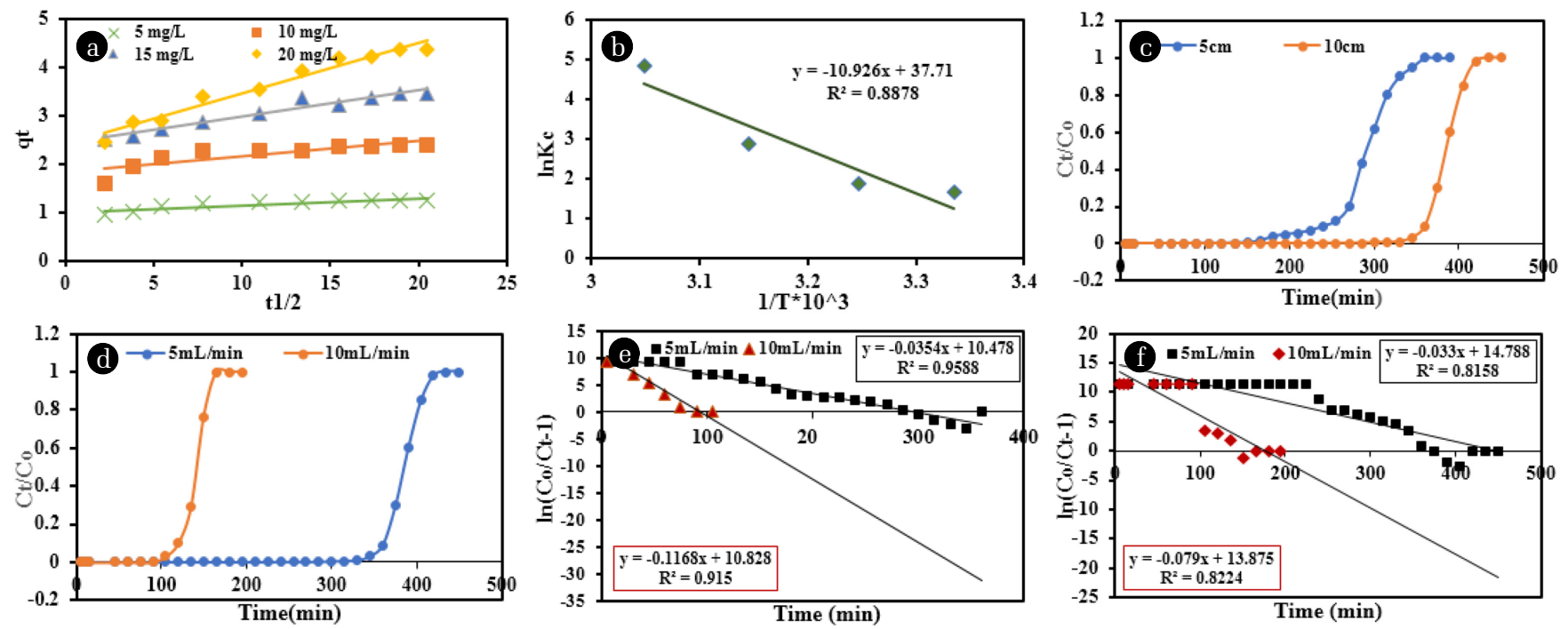

Fig. 4. (a) Plot of Intraparticle Diffusion Model, (b) Plot of Thermodynamic, (c) Breakthrough curve for effect of bed height on MPPAC-500, (d) effect of flow rate on MPPAC-500, (e) Thomas model of MPPAC-500 at $5 \mathrm{~cm}$ bed height, (f) Thomas model of MPPAC-500 at 10 $\mathrm{cm}$ bed height.

Table 3. Values of different fixed bed and Thomas model parameters

\begin{tabular}{|c|c|c|c|c|c|c|c|c|c|c|}
\hline \multicolumn{8}{|c|}{ Column parameters } & \multicolumn{3}{|c|}{ Thomas parameters } \\
\hline $\begin{array}{c}\mathrm{C}_{\mathrm{o}} \\
\left(\mathrm{mg} \mathrm{L}^{-1}\right)\end{array}$ & $\begin{array}{c}\mathrm{Z} \\
(\mathbf{c m})\end{array}$ & $\frac{\mathrm{Q}}{\left(\mathrm{mL} \min ^{-1}\right)}$ & $\begin{array}{c}t_{\text {total }} \\
(\mathrm{min})\end{array}$ & $\begin{array}{l}\mathbf{m}_{\text {total }} \\
\text { (mg) }\end{array}$ & $\begin{array}{l}\text { qtotal } \\
\text { (mg) }\end{array}$ & $\begin{array}{c}\text { qeq } \\
(\mathrm{mg} / \mathrm{g})\end{array}$ & $\begin{array}{c}V_{\text {eff }} \\
(\mathrm{mL})\end{array}$ & $\begin{array}{c}\text { KTH } \\
\left(\mathrm{mL} \min ^{-1} \mathrm{mg}^{-1}\right)\end{array}$ & $\begin{array}{c}\mathrm{Q}_{\mathbf{0}} \\
\left(\mathrm{mg} \mathrm{g}^{-1}\right)\end{array}$ & $\mathbf{R}^{2}$ \\
\hline 10 & 5 & 5 & 360 & 18 & 17.9982 & 3.7497 & 1800 & 0.00354 & 3083.21 & 0.9588 \\
\hline 10 & 5 & 10 & 105 & 10.5 & 10.4998 & 2.1878 & 1050 & 0.01168 & 1931.37 & 0.951 \\
\hline 10 & 10 & 5 & 450 & 22.5 & 22.4998 & 2.3438 & 2250 & 0.0033 & 2327.7 & 0.9043 \\
\hline 10 & 10 & 10 & 195 & 19.5 & 19.4998 & 2.0313 & 1950 & 0.0079 & 1829.38 & 0.8224 \\
\hline
\end{tabular}

ter are presented in Table 3. When the bed depth was increased from $5 \mathrm{~cm}$ to $10 \mathrm{~cm}$, saturation time from $345 \mathrm{~min}$ to $420 \mathrm{~min}$ and treated effluent volume from $1,800 \mathrm{~mL}$ to $2,250 \mathrm{~mL}$ and the breakthrough time from $135 \mathrm{~min}$ to $285 \mathrm{~min}$ were increased, which due to available adsorption sites of the adsorbent were increased for uptake of fluoride ions.

\subsubsection{Effect of flow rate}

To evaluate the effect of volumetric flow rate of inlet Fluoride ions on the capacity adsorption and breakthrough curve for MPPAC-500. The operational experiments were implemented at two different flow rates $(5 \mathrm{~mL} / \mathrm{min}$ and $10 \mathrm{~mL} / \mathrm{min}$ ), although experimental parameters were placed on concentration $10 \mathrm{mg} / \mathrm{L}$ and $10 \mathrm{~cm}$ bed height are constant. Obtained breakthrough curve shown in Fig. 4(d) and other breakthrough curve parameters such as breakthrough time, saturation time were appraised and treated volume was epitomized in Table 3. It is clear from the Fig. 4(d) that increasing the feed fluoride ions flow rate decreases the breakthrough time and exhaustion time, experimental results indicate when the flow rate increased which decreases breakthrough time and saturation time, because at high flow rate adsorbate have not enough time to contact with adsorbent bed in the column. The result show that higher breakthrough time, saturation time, treated volume was found at lower flow rate because at low flow rate solute has more residence time to pores of the adsorbent.

\subsubsection{Thomas model}

Thomas model employed to predict column performance and breakthrough curves [41]. The model relied on with Langmuir kinetic of adsorption and desorption process [42, 43]. This model also describes constant separation factor which applied either favourable or unfavourable isotherms [41]. The linear Eq. (18) of Thomas model is given as below.

$$
\ln \left(\frac{C_{o}}{C_{t}}-1\right)=\frac{k_{T H} q_{e} x}{Q}-k_{T H} C_{o} t
$$

Where, $k_{T H}$ (mL/min.mg) is the rate constant for Thomas; $Q$ $(\mathrm{mL} / \mathrm{min})$ is flow rate of the solution; $q_{e}(\mathrm{mg} / \mathrm{g})$ is the adsorption capacity and $\mathrm{x}(\mathrm{g})$ is the mass of adsorbent.

Fig. $4(\mathrm{e})$ shows the linear plot of $\ln \left[\left(\mathrm{C}_{\mathrm{i}} / \mathrm{C}_{\mathrm{t}}\right)-1\right]$ vs ' $t$ '. The values obtained from Thomas models were shown in Table 3 . It can be stated that as increasing in flow rates from 5-10 $\mathrm{mL} \mathrm{min}^{-1}$ at bed height of $5 \mathrm{~cm}$, the values of $K_{T H}$ increased and $q_{o}$ decreased shown in Fig. 4(f). The reason of increased values of $K_{T H}$ and decreased 
value of $q_{o}$ is due to the driving force between adsorbate and adsorbent. Similar results were also observed at $10 \mathrm{~cm}$ bed height for Fluoride adsorption in the solution [44]. These results revealed that lower the flow rates with higher bed height leads to maximum fluoride uptake on to adsorbent.

\subsubsection{Adams-Bohart Model}

This model assume that adsorption rate is proportional to the concentration of the adsorbate (fluoride) and residual capacity of the adsorbent. The equation of Adams-Bohart model in linear form is given in Eq. (19).

$$
\ln \left(\frac{C_{o}}{C_{t}}-1\right)=k_{A B} N_{o} \frac{z}{\mu_{o}}-k_{A B} C_{o} t
$$

Where, $\mathrm{N}_{\mathrm{o}}$ is the maximum uptake capacity of the adsorbent per unit volume in the column; $\mathrm{k}_{\mathrm{AB}}$ is the rate constant for Adams-Bohart and $\mu_{\mathrm{o}}$ is the linear flow rate of the influent solution (cm/min).

\subsubsection{Yoon-Nelson model}

Yoon- Nelson model stipulates the adsorption kinetic of a fixed bed. This model assumes that the rate decrease in the probability of adsorption for particular sorbate molecule is proportional to the probability of sorbate breakthrough and the probability of the sorbate (fluoride) adsorption. The linearized equation is presented as below.

$$
\ln \left(\frac{C_{t}}{C_{o}-C_{t}}\right)=k_{Y N} t-K_{Y N} \tau
$$

Where $\mathrm{k}_{\mathrm{YN}}(1 / \mathrm{min})$ is the rate constant for Yoon-Nelson and $\tau$ (min) is taken for $50 \%$ adsorbate breakthrough.

\subsubsection{Clark model}

This model introduced by Clark for fixed bed column adsorption. The mass transfer can be evaluated with the help of Freundlich parameter (n). Clark equation is presented as below.

$$
\ln \left[\left(\frac{C_{o}}{C_{t}}\right)^{n-1}-1\right]=\ln A-r t
$$

Where, A and $\mathrm{r}(1 / \mathrm{h})$ is the Clark constant, and $\mathrm{n}$ is the parameter of Freundlich. The value of these constant can obtain from the intercept and slope of the graph plotted $\left.\ln \left[C_{0} / C_{t}\right)^{\mathrm{n}-1}-1\right]$ vs time (min).

The parameters of Adams-Bohart, Yoon-Nelson and Clark models are given in supplementary data (Table S2, S3 and S4, respectively) and plot of these model is shown in Fig. S5, S6 and S7, respectively. Adams-Bohart model revealed that the rate constant increased as the bed depth of adsorbent increases. While, adsorption capacity $\left(\mathrm{N}_{\mathrm{o}}\right)$ decreased. The rate constant $\left(\mathrm{K}_{\mathrm{YN}}\right)$ of Yoon-Nelson and (time needed for 50\% adsorbate breakthrough decreased with increasing flow rate, while increased with increasing adsorbent dose. The Clark parameter (r) increased with increasing flow rate.

\section{Possible Fluoride Adsorption Mechanism on MPPAC-500}

Adsorption mechanism leads to either physical or chemical adsorption in aqueous systems. Physical adsorption tends on the surface of adsorption due to Van der Waals force. Chemical adsorption occurs between adsorbent and adsorbate due to chemical bonding including ion exchange, complexation and electrostatic interaction that are generally taken place on adsorbent surface [45]. It is evident from Fig. 2(c) FTIR spectra both after and before adsorption, -CH (methyl), - $\mathrm{OH}$ (hydroxyl) and $>\mathrm{C}=\mathrm{O}$ (Ketone) groups are present, Wang et al. [46] reported that these groups play major role in $\mathrm{F}^{-}$adsorption due to complexation mechanism. The ionic radius of fluoride and hydroxyl having same size, and the bonding affinity of $\mathrm{F}^{-}$is higher than hydroxyl ion. Therefore, the ion exchange formation takes place by bonding between adsorbent and adsorbate [47]. Hydrogen bonding may occur between - $\mathrm{OH}$ group and fluoride ion. Based on EDX spectra (Fig. 2(a)), the presence of iron peak confirms the presence of iron in modified adsorbent and XRD analysis also confirm presence of iron in the MPPAC-500 by several peaks at $23.58^{\circ}, 32.72^{\circ}$ and $35.74^{\circ}$ that are characteristic peak for presence of $\mathrm{Fe}$ in the form of iron and iron oxide. Reported that iron impart positive charged to the adsorbent that electrically attract the negatively charge fluoride ions. A proposed adsorption mechanism for fluoride on MPPAC500 is shown in Fig. 5.

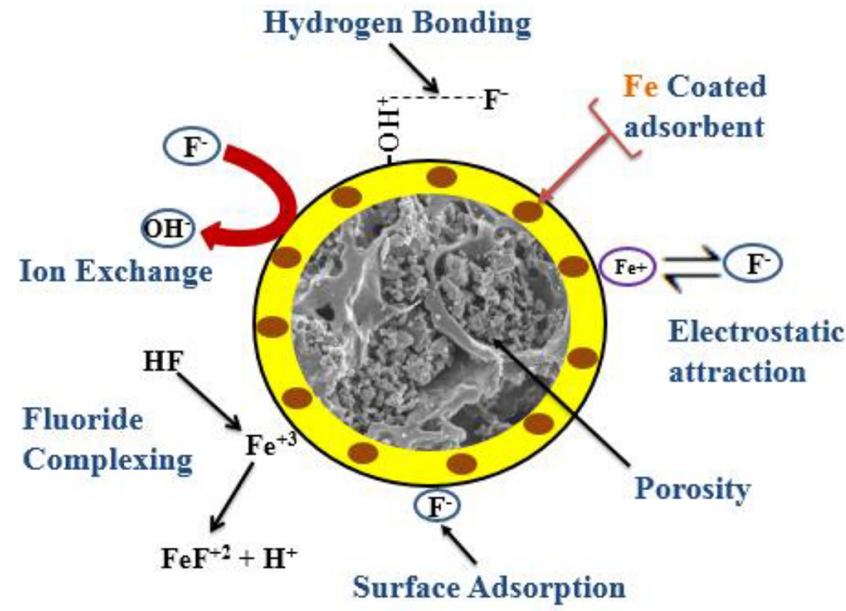

Fig. 5. Possible adsorption mechanism of fluoride on MPPAC-500.

\section{Conclusions}

This work explored the applicability of waste pea peel as novel adsorbent for the elimination of fluoride ions from aqueous medium. The pea peel was modified with iron $\left(\mathrm{FeCl}_{3}\right)$ for enhancing its adsorption efficiency. Surface characterization explored the existence of heterogeneous structure, showing small and large pore, provides exchangeable sites for adsorption. Infrared Spectroscopy results demonstrated the role of hydroxyl, methyl and ketone groups were involved in the removal of fluoride. In batch study, the 
maximum fluoride removal 99\% was found at $5 \mathrm{mgL}^{-1}$ initial fluoride concentration at neutral $\mathrm{pH}, 4 \mathrm{gm} / \mathrm{L}$ dose, and 420 min contact time. Adsorption study favoured Freundlich isotherm model. Fluoride uptake was well described with pseudo-second-order kinetic model. Thermodynamic parameters indicated that the adsorption process was followed endothermic and spontaneous in nature. The column study results were fitted well with Adams- Bohart model followed by Thomas model. The maximum removal capacity at column system was found $3.75 \mathrm{mg} / \mathrm{g}$. The present adsorbent shows the efficient adsorptive capacity for uptake of fluoride in batch and column systems, which may suggest for remediation of fluoride from groundwater and contaminated surface water by biomass based biosorbent is highly recommended.

\section{Acknowledgment}

The research work was financially supported by Department of Science and Technology (DST) Science and Engineering Research Board (SERB), India. (Reference no. ECR/2016/001924).

\section{Author Contributions}

Ms. N.S. (Project Assistant), has conducted all the experiments and writing work, Mr. C.B. (Ph.D) has drafted the manuscript and Dr. J.S. (Assistant Professor) has supervised the work and corrected the manuscript.

\section{References}

1. Inanya M, Raychoudhury T. Application of activated carbonmetal composite for fluoride removal from contaminated groundwater in India. Int. J. Environ. Sci. Technol. 2019;16: 7545-7554.

2. Chandrajith R, Padmasiri J, Dissanayake C, Prematilaka K. Spatial distribution of fluoride in groundwater of Sri Lanka. J. Natl. Sci. Found. Sri Lanka. 2012;40:303-309.

3. Craig L, Stillings LL, Decker DL, Thomas JM. Comparing activated alumina with indigenous laterite and bauxite as potential sorbents for removing fluoride from drinking water in Ghana. Appl. Geochem. 2015;56:50-66.

4. WHO. Chemical Fact Sheets: Fluoride, Guidelines for Drinking Water Quality (Electronic Resource), vol. 1., third edition Incorporation First Addendum, Recommendations, Geneva, 2006;375-377.

5. Liu J, Zhao P, Xu Y, Jia X. Mg-Al Mixed Oxide Adsorbent Synthesized Using FCT Template for Fluoride Removal from Drinking Water. Bioinorg. Chem. Appl. 2019; 5840205:1-11.

6. Hanse A, Chabukdhara M, Baruah SG, Boruah H, Gupta SK. Fluoride contamination in groundwater and associated health risks in Karbi Anglong District, Assam, Northeast India. Environ. Monitor. Assess. 2019;191:782.

7. Parashar K, Pillay K, Das R, Maity A. Fluoride Toxicity and Recent Advances in Water Defluoridation with Specific Emphasis on Nanotechnology. In Emerg. Nanostruct. Mater.
Energy. Environ. Sci. 2019;395-442.

8. Ayoob S, Gupta AK. Fluoride in drinking water: a review on the status and stress effects. Crit. Rev. Env. Sci. Tec. 2006;36: 433-487.

9. Jagtap S, Yenkie MK, Labhsetwar N, Rayalu S. Fluoride in drinking water and defluoridation of water. Chem. Reviews. 2012;112:2454-2466.

10. Malik DS, Jain CK, Yadav AK. Removal of heavy metals from emerging cellulosic low-cost adsorbents: a review. Appl. Water Sci. 2017;7:2113-2136.

11. Sujana MG, Soma G, Vasumathi N, Anand S. Studies on fluoride adsorption capacities of amorphous $\mathrm{Fe} / \mathrm{Al}$ mixed hydroxides from aqueous solutions. J. Fluorine Chem. 2009;130:749-754.

12. Ramos RL, Ovalle-Turrubiartes J, Sanchez-Castillo MA. Adsorption of fluoride from aqueous solution on aluminum-impregnated carbon. Carbon 1999;37:609-617.

13. Deng S, Liu H, Zhou W, Huang J, Yu G. Mn-Ce oxide as a high-capacity adsorbent for fluoride removal from water. J. Hazard. Mater. 2011;186:1360-1366.

14. Naushad M, Ahamad T, Sharma G, et al. Synthesis and characterization of a new starch/SnO2 nanocomposite for efficient adsorption of toxic Hg2+ metal ion. Chem. Eng. J. 2016;300:306-316.

15. Sivarajasekar N, Paramasivan T, Muthusaravanan S, Muthukumaran P, Sivamani S. Defluoridation of water using adsorbents - a concise review. J. Environ. Biotechnol. Res. 2017;6:186-198.

16. Mohamed WSED, Hamad MTMH, Kamel MZ. Application of statistical response surface methodology for optimization of fluoride removal efficiency by Padina sp. Alga. Water Environ. Res. 2020;92:1080-1088.

17. Li HF, Cui F, Zhang J, et al. Preparation and DEA removal performance of iron-modified activated carbon. Int. J. Environ. Sci. Technol. 2019;16:2927-2936.

18. Dai G, Gan N, Song L. Fast adsorption of microcystin-LR by Fe(III)-modified powdered activated carbon. J. Ocean. Limnol. 2018;36:1103-1111.

19. Talat M, Mohan S, Dixit V, Singh DK, Hasan SH, Srivastava ON. Effective removal of fluoride from water by coconut husk activated carbon in fixed bed column: Experimental and breakthrough curves analysis. Groundw. Sustain. Dev. 2018;7:48-55.

20. Mullick A, Neogi S. Acoustic cavitation induced synthesis of zirconium impregnated activated carbon for effective fluoride scavenging from water by adsorption. Ultrason. Sonochem. 2018;45:65-77.

21. Dehghani MH, Farhang M, Alimohammadi M, Afsharnia M, Mckay G. Adsorptive removal of fluoride from water by activated carbon derived from CaCl2-modified Crocus sativus leaves: Equilibrium adsorption isotherms, optimization, and influence of anions. Chem. Eng. Commun. 2018;7:955-965.

22. Mohanta D, Ahmaruzzaman M. Bio-inspired adsorption of arsenite and fluoride from aqueous solutions using activated carbon@SnO2 nanocomposites: isotherms, kinetics, thermodynamics, cost estimation and regeneration studies. J. Environ. Chem. Eng. 2018;6:356-366.

23. Lung S, Singh S, Sinha A. Magnetic iron oxide (Fe3O4) nanoparticles from tea waste for arsenic removal. J. Magn. Magn. Mater. 2014;356:21-31. 
24. Chen S, Yue Q, Gao B, et al. Adsorption of hexavalent chromium from aqueous solution by modified corn stalk: a fixed-bed column study. Bioresour. Technol. 2012;113:114-120.

25. Adetokun AA, Uba S, Garba ZN. Optimization of adsorption of metal ions from a ternary aqueous solution with activated carbon from Acacia senegal (L.) Willd pods using Central Composite Design. J. King Saud Univ. Sci. 2018;31:1452-1462.

26. Bishnoi S, Kumar A, Selvaraj R. Facile synthesis of magnetic iron oxide nanoparticles using inedible Cynometra ramiflora fruit extract waste and their photocatalytic degradation of methylene blue dye. Mater. Res. 2018;97:121-127.

27. Anyika C, Asri NAM, Majid ZA, Yahya A, Jaafar J. Synthesis and characterization of magnetic activated carbon developed from palm kernel shells. Nanotechnol. Env. Eng. 2017;2:16.

28. Mahmood T, Aslam M, Naeem A, Siddique T, Din SU. Adsorption of As (III) from aqueous solution onto iron impregnated used tea activated carbon: Equilibrium, kinetic and thermodynamic study. J. Chil. 2018;63:3855-3866.

29. Yusuff SA. Optimization of adsorption of $\mathrm{Cr}(\mathrm{VI})$ from aqueous solution by Leucaena leucocephala seed shell activated carbon using design of experiment, Appl. Water Sci. 2018;8:232.

30. Sahu N, Rawat S, Singh J, et al. Process Optimization and Modeling of Methylene Blue Adsorption Using Zero-Valent Iron Nanoparticles Synthesized from Sweet Lime Pulp. Appl. Sci. 2019;9:5112.

31. Singh J, Reddy KJ, Chang YY, Kang SH, Yang JK. A novel reutilization method for automobile shredder residue as an adsorbent for the removal of methylene blue: Mechanisms and heavy metal recovery using an ultrasonically assisted acid. Process Safe. Environ. Prote. 2016;99:88-97.

32. Yadav N, Dhruv NM, Rawat S, Singh J. Adsorption and equilibrium studies of phenol and para-nitrophenol by magnetic activated carbon synthesised from cauliflower waste. Environ. Eng. Res. 2019;25:742-752.

33. Yadav AK, Abbassi R, Gupta A, Dadashzadeh M. Removal of fluoride from aqueous solution and ground water by wheat straw, sawdust and activated bagasse carbon of sugar. Ecol. Eng. 2013;52:211-28.

34. Suneetha M, Sundar BS, Ravindhranath K. Removal of Fluoride from polluted waters Using Active Carbon Derived From Barks Of Vitex Negundo Plant. J. Analy. Sci. Technol. 2015;6:2-19.

35. Kazi TG, Brahman KD, Baig JA, Afridi HI. A new efficient indigenous material for simultaneous removal of fluoride and inorganic arsenic species from groundwater. J. Hazard. Mater.
2018;357:159-167.

36. Singh J, Lee BK. Recovery of precious metals from low-grade automobile shredder residue: A novel approach for the recovery of nanozero-valent copper particles. Waste Manage. 2016;48:353-365.

37. Mondal NK, Samanta A, Roy P, Das B. Optimization study of adsorption parameters for removal of $\mathrm{Cr}$ (VI) using Magnolia leaf biomass by response surface methodology. Sustain. Water Resour. Manag. 2019;5:1627-1639.

38. Dada AO, Olalekan AP, Olatunya AM, Dada OJIJC. Langmuir, Freundlich, Temkin and Dubinin-Radushkevich isotherms studies of equilibrium sorption of $\mathrm{Zn} 2+$ unto phosphoric acid modified rice husk. IOSR J. Appl. Chem. 2012;3:38-45.

39. Getachew T, Hussen A, Rao VM. Defluoridation of water by activated carbon prepared from banana (Musa paradisiaca) peel and coffee (Coffea arabica) husk. Int. J. Environ. Sci. Technol. 2015;12:1857-1866.

40. Du J, Bao J, Hassan MA, Irshad S, Talib MA. Multi-functional biochar novel surface chemistry for efficient capture of anionic congo red dye, Behaviour and mechanism. Arabian J. Sci. Eng. 2019;44:10127-10139.

41. Sadaf S, Bhatti HN. Batch and fixed bed column studies for the removal of Indosol yellow BG dye by peanut husk. J. Taiwan Inst. Chem. Engine. 2014;45:541-553.

42. Malik DS, Jain CK, Yadav AK. Heavy Metal Removal by Fixed-Bed Column - A Review. ChemBioEng Reviews. 2018;5: 173-179.

43. Basu M, Guha AK, Ray L. Adsorption of lead on lentil husk in fixed bed column reactor. Bioresour. Technol. 2019;283:86-95.

44. Charola S, Yadav R, Das P, Maiti S. Fixed- bed adsorption of reactive orange 84 dye onto activated carbon prepared from empty cotton flower agro waste. Sustain. Environ. Res. 2018;28:298-308.

45. Starrinou A, aggelopoulas CA, Tsakiroglou CD. Exploring the adsorption mechanism of cationic and anionic dyes onto agricultural waste peels oof banana, cucumber and potato: Adsorption, kinetics and equilibrium. J. Environ. Chem. Eng. 2018;6: 6958-6970.

46. Wang Li, Wang Y, Ma F, et al. Mechanism and reutilization of modified biochar used for removal of heavy metals from waste water: A review. Sci. Total Environ. 2019;668:1298-1309.

47. Zhu J, Lin X, Wu P, Zhou Q, Luo X. Fluoride removal from aqueous solution by $\mathrm{Al}(\mathrm{III})-\mathrm{Zr}(\mathrm{IV})$ binary ixide adsorbent. Appl. Surf. Sci. 2015;357:91-100. 